\title{
Fractal Analysis of Three-dimensional Fracture Surfaces in Metals and Ceramics
}

\author{
M. TANAKA, Y. KIMURA, ${ }^{1)}$ A. KAYAMA, ${ }^{2)}$ R. KATO and J. TAGUCHI ${ }^{3)}$ \\ Department of Mechanical Engineering, Akita University, 1-1, Tegatagakuen-cho, Akita 010-8502 Japan. \\ 1) Nippon System Ware Company, 31-11, Sakuragaoka-cho, Shibuya-ku, Tokyo 150-8577 Japan. \\ 2) Michelin Research Asia, 880, Uekino-cho, Ohta, Gunma Pref. 373-8668 Japan. \\ 3) Graduate School, Akita University, 1-1, Tegatagakuen-cho, Akita 010-8502 Japan.
}

(Received on January 30, 2004; accepted in final form on April 15, 2004)

\begin{abstract}
Three-dimensional images of fracture surfaces formed by different mechanisms were reconstructed by the computer-aided stereo matching method on metals and ceramics. The fractal dimension of the three-dimensional fracture surface was estimated by the box-counting method using the height data generated by the stereo matching method. The ductile fracture surface (stage I fatigue) had the larger fractal dimension compared with the brittle-type fracture surface (stage II fatigue) in a Cu-Be alloy. However, it was difficult to classify the type of fracture, namely, ductile fracture or brittle-type fracture, in different materials only by the fractal dimension of the fracture surface, since even fractal dimensions of brittle-type fracture surfaces exhibited different values with different materials, depending on the fracture mechanisms of materials. There was a good correlation between the results of the three-dimensional fractal analysis and those of the twodimensional fractal analysis on materials. The value of the fractal dimension of the three-dimensional fracture surface depends not only on the size of the analyzed area but also on the algorithms of the fractal analysis. The fractal dimension estimated in a given length scale range can be correlated with specific microstructures in materials.
\end{abstract}

KEY WORDS: three-dimensional fracture surface; fractal dimension; metals; ceramics; stereo matching method.

\section{Introduction}

Fractal geometry created by Mandelbrot ${ }^{1)}$ enabled the quantitative description of various objects in nature. Fractal geometry has also been applied to the interpretation of physical phenomena such as fracture, ${ }^{2)}$ grain growth ${ }^{3)}$ and grain-boundary migration ${ }^{4}$ in solids. Various techniques have been proposed for the estimation of the fractal dimension of microstructures and fracture surfaces in materials. $^{1,5-8)}$ Almqvist ${ }^{7)}$ proposed the variance method for the estimation of the fractal dimension, $D_{\mathrm{v}}\left(2<D_{\mathrm{v}}<3\right)$, of the three-dimensional surface on the images obtained by scanning probe microscopes (SPMs). However, the SPMs seem to be not suitable for the characterization of very complex surfaces with bumps and ledges such as fracture surfaces in metals.

A computer-aided stereo matching method using a stereo pair (scanning electron micrographs) has successfully been applied to the reconstruction and analysis of complex threedimensional fracture surfaces in materials. ${ }^{9-12)}$ Kimura et $a l{ }^{13,14)}$ have developed a new stereo matching method based on the coarse-to-fine format, which enables the reconstruction of three-dimensional images with a reasonable accuracy in a short time. Further, Tanaka et al. ${ }^{15)}$ have recently developed a computer program of the box-counting method for the fractal analysis of the three-dimensional fracture surfaces.

The fracture surface patterns are generally correlated with the microstructures of materials in the two-dimensional fractal analysis. ${ }^{16-18)}$ It is known that certain fracture surface has some values of the fractal dimensions (multi-fractal nature) depending on the length scale range of the fractal analysis. ${ }^{16,19-21)}$ Therefore, it is necessary to estimate the fractal dimension in the length scale range that is associated with the size of microstructures in materials. Further, the size of the analyzed area may also affect the value of the fractal dimension. ${ }^{7)}$

In this study, the fractal dimension was estimated by the box-counting method on the three-dimensional fracture surfaces of metals and ceramics reconstructed by the stereo matching method. The results of the three-dimensional fractal analysis by the box-counting method were compared with those obtained by the variance method or the results of the two-dimensional fractal analysis. A discussion was then made on the relations between the microstructures, the analyzed area, the fracture mechanisms and the fractal dimension. 


\section{Experimental and Analytical Methods}

\subsection{Materials and Experiments}

Metallic materials used for the fractal analysis are the austenitic SUS316 steel (the average grain size is about $\left.1.3 \times 10^{-5} \mathrm{~m}\right)^{22,23)}$ a $\mathrm{Cu}-\mathrm{Be}$ alloy (the average grain size is about $\left.2.4 \times 10^{-5} \mathrm{~m}\right)^{22)}$ and a pure $\mathrm{Zn}$ polycrystals (the average grain size is about $\left.1.2 \times 10^{-5} \mathrm{~m}\right){ }^{24)}$ Ceramics used are a silicon carbide ( $\mathrm{SiC}$, the average grain size is about $1.3 \times 10^{-5} \mathrm{~m}$ ) (Norton NC-430), ${ }^{25,26)}$ a commercial alumina $(\mathrm{SSA}-\mathrm{H})$ (the average grain size is about $3.0 \times 10^{-6} \mathrm{~m}$ ) and a commercial mullite (the average grain size is unknown). SSA-H alumina is often used for heat insulator of thermocouples. Fatigue fracture surface of the SUS316 steel and that of a $\mathrm{Cu}-\mathrm{Be}$ alloy were produced by repeated bending on the rectangular specimen $(1.5 \mathrm{~mm}$ thickness, $10 \mathrm{~mm}$ width and $144 \mathrm{~mm}$ length) at the maximum total strain range (on the specimen surface) of 0.0169 for the SUS316 steel $^{22,23)}$ and at that of 0.0171 for a $\mathrm{Cu}-\mathrm{Be}$ alloy, respectively. Creep-rupture experiments of pure $\mathrm{Zn}$ polycrystals were carried out under a stress of $14.7 \mathrm{MPa}$ at $373 \mathrm{~K}^{24)}$ Fracture surfaces of a silicon carbide (Norton NC-430), an alumina (SSA-H) and a mullite were produced by impact loading. Photographs of stereo pairs (the basic image and the tilted image by $10 \mathrm{deg}$.) on fracture surfaces were taken using a scanning electron microscope (SEM). The photographs were then taken into a computer and were converted to the digital images of 256 grey scale levels. Three-dimensional image reconstruction was carried out to obtain the height data of fracture surfaces using stereo pair images by the stereo matching method. The details of the stereo matching method are described in the reference. ${ }^{13,14)}$

\subsection{Analytical Methods}

A computer program of the box-counting method, which had been developed in the previous study, ${ }^{15)}$ was used for the estimation of the fractal dimension of the three-dimensional fracture surface in this study. The fractal analysis was made using the height data of the reconstructed threedimensional images in this study. The number of boxes, $N$, covering the fracture surface can be related to the box size, $r$, through the three-dimensional fractal dimension, $D_{\mathrm{b}}$, by the following power law relationship:

$$
N \propto r^{-D_{\mathrm{b}}} \quad \text { or } \quad \log N \propto-D_{\mathrm{b}} \log r
$$

The fractal dimension, $D_{\mathrm{b}}$, can be calculated from Eq. (1) by the regression analysis using the datum sets of $N$ and $r$. The height images generated by the stereo matching method were actually used for the estimation of the fractal dimension of the three-dimensional fracture surface in materials. ${ }^{15)}$ Figure 1 shows examples of the relationship between the number of boxes, $N$, covering the fracture surface and the box size, $r$, on materials in the box-counting method (stage I and stage II fatigue fracture surfaces in a $\mathrm{Cu}-\mathrm{Be}$ alloy). The length scale of the fractal analysis is in the range from two pixels to the analyzed area in this case. Fractal analysis by the variance method was also carried out for comparison on these materials.

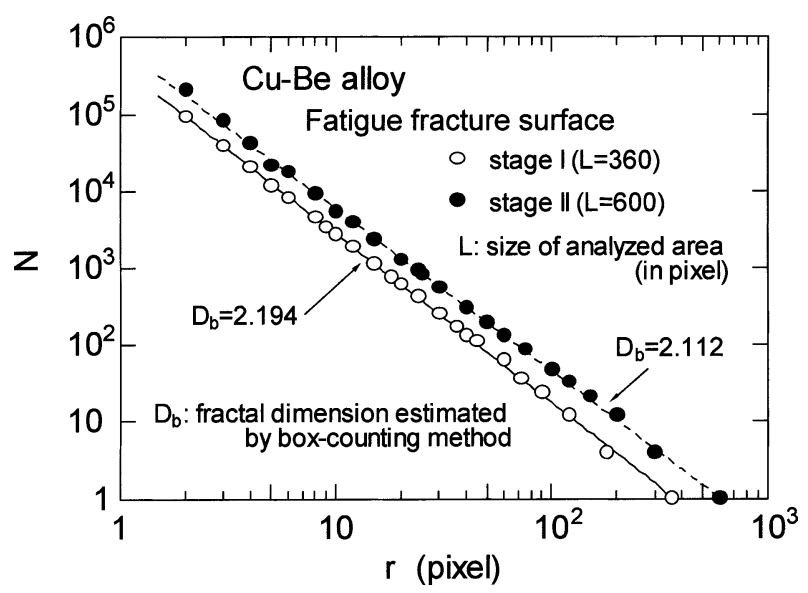

Fig. 1. Examples of the relationship between the number of boxes, $N$, covering the fracture surface and the box size, $r$, on materials in the box-counting method (stage I and stage II fatigue fracture surfaces in a $\mathrm{Cu}-\mathrm{Be}$ alloy).
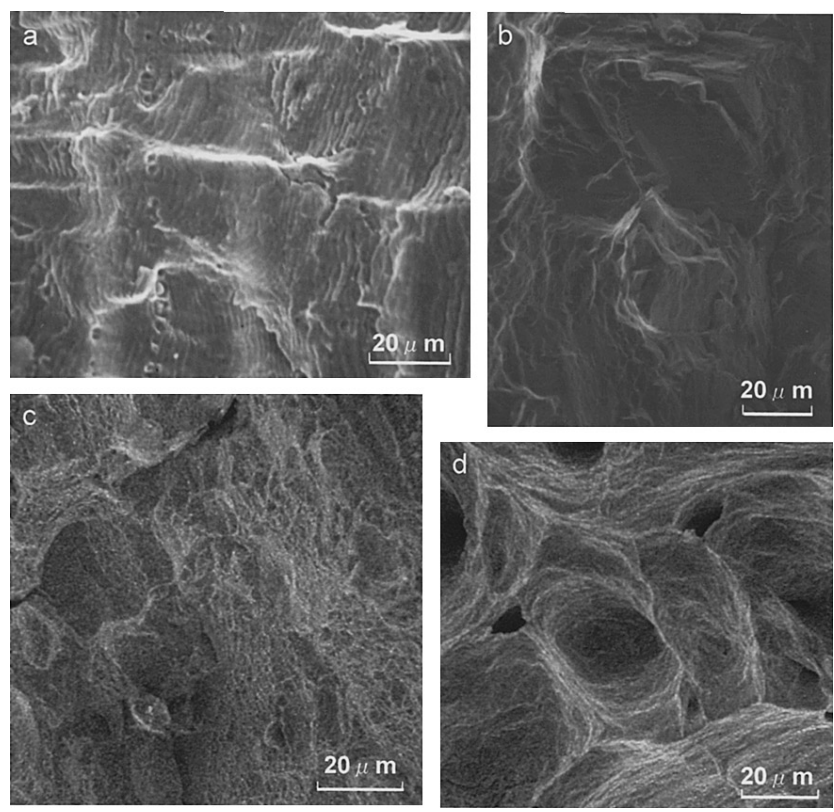

Fig. 2. Scanning electron micrographs of fracture surfaces in metallic materials (a) is the stage II fatigue fracture surface of SUS316 steel (the maximum total strain range is 0.0169); (b) is the stage I fatigue fracture surface and (c) is the stage II fatigue fracture surface of a $\mathrm{Cu}-\mathrm{Be}$ alloy (the maximum total strain range is 0.0171 ); (d) is a creep fracture surface of pure $\mathrm{Zn}$ polycrystals (ruptured at $373 \mathrm{~K}, 14.7 \mathrm{MPa}$ ).

\section{Results and Discussion}

\subsection{Fracture Surfaces of Materials}

Figure 2 shows the scanning electron micrographs of fracture surfaces in metallic materials. These micrographs were used as the basic images for the three-dimensional image reconstruction by the stereo matching method. The direction of fatigue crack growth is approximately from right to left in Figs. 2(a), 2(b) and 2(c). Striations and steps are typical patterns of the stage II fatigue fracture surface of the SUS316 steel (Fig. 2(a)). ${ }^{22,23)}$ In a Cu-Be alloy, the stage I fatigue fracture surface is formed for the most part in a ductile manner with slip steps and dimples except small grain-boundary facets in the middle part of the mi- 

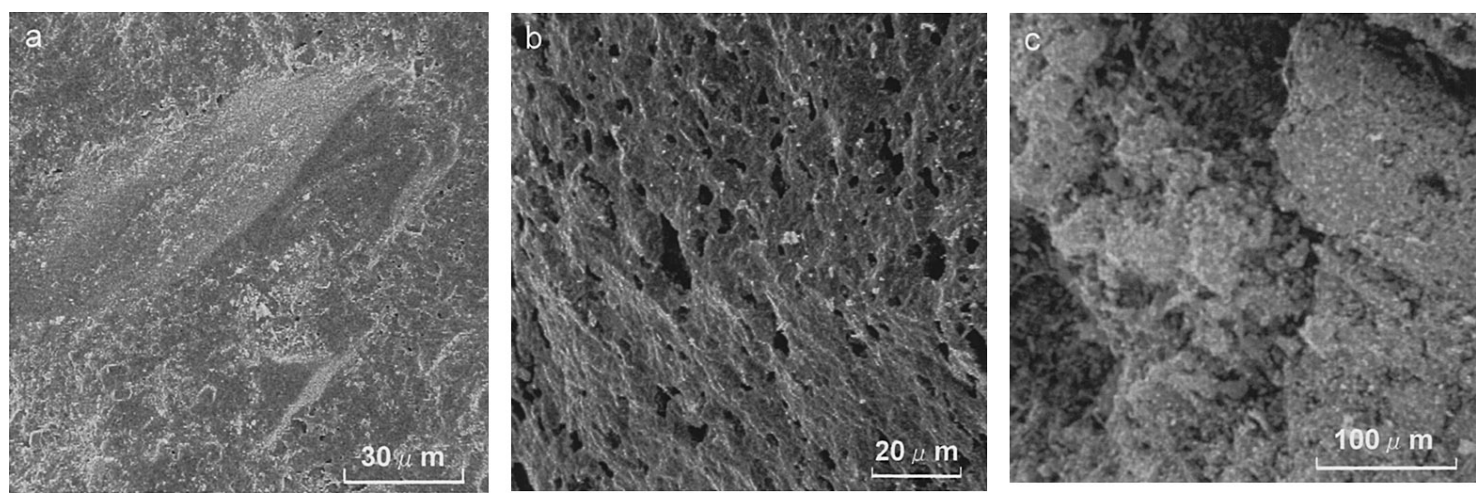

Fig. 3. Scanning electron micrographs of impact fracture surfaces in ceramics. (a) is a silicon carbide ( $\mathrm{SiC}$ ) (Norton NC430); (b) is a commercial alumina (SSA-H); (c) is a commercial mullite.
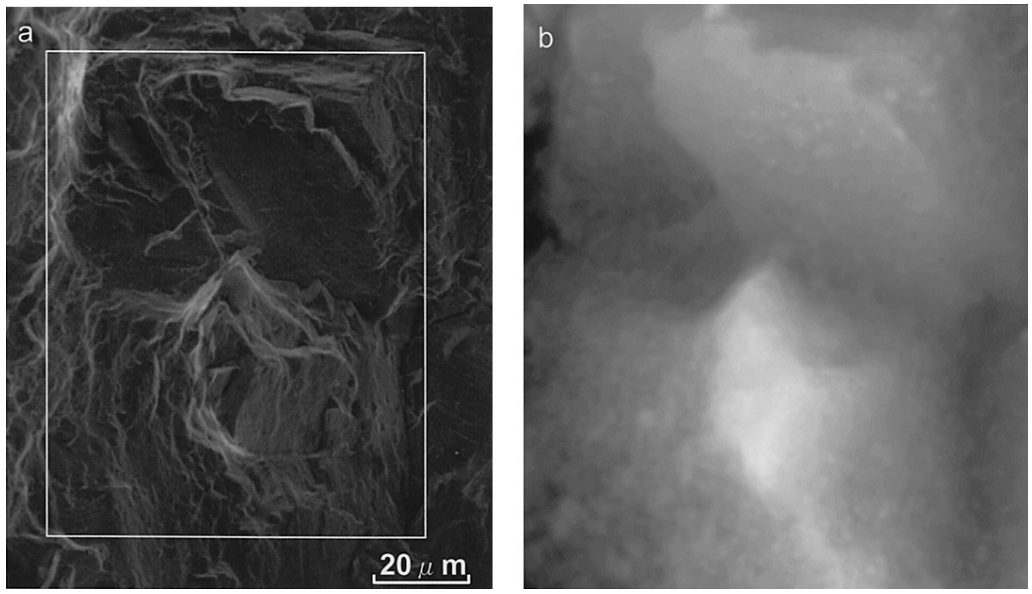

Fig. 4. The original image and the height image generated by the three-dimensional (3D) image reconstruction (stage I fatigue fracture surface of a $\mathrm{Cu}-\mathrm{Be}$ alloy). (a) is the computed region (enclosed by white lines, $403 \times 467$ in pixel); (b) is the height image generated by $3 \mathrm{D}$ image reconstruction.

crograph (Fig. 2(b)), while the stage II fatigue fracture surface is brittle-type with grain-boundary facets and fine dimples (Fig. 2(c)). ${ }^{22)}$ Creep fracture surface of pure Zn polycrystals is composed of equi-axed dimples of various sizes (Fig. 2d). ${ }^{24)}$ Figure 3 shows the scanning electron micrographs of fracture surfaces in ceramics. These micrographs of impact fracture surfaces were also used for the three-dimensional image reconstruction. A silicon carbide (Norton NC-430) is composed of many $\mathrm{SiC}$ grains of various sizes with a small amount of residual metallic silicon. ${ }^{25,26)}$ Brittle fracture may occur along the interface between large a $\mathrm{SiC}$ grain and metallic silicon in the silicon carbide (flat region in the middle part of Fig. 3(a)), while ductile fracture may occur in metallic silicon. Micropores, which may be formed during sintering process, can be observed on the brittle fracture surface of an alumina (SSA-H) (Fig. 3(b)). A mullite exhibits a complicated fracture surface with micropores (Fig. 3(c)).

\subsection{Fractal Analysis of Three-dimensional Fracture Surfaces}

Figure 4 shows the original image and the height image generated by the stereo matching method on the stage I fatigue fracture surface of a $\mathrm{Cu}-\mathrm{Be}$ alloy cited from the previous study. ${ }^{14)}$ The computed area is also shown in Fig. 4(a). The brighter part corresponds to the higher region on the fracture surface in the height image (Fig. 4(b)). Figure 5

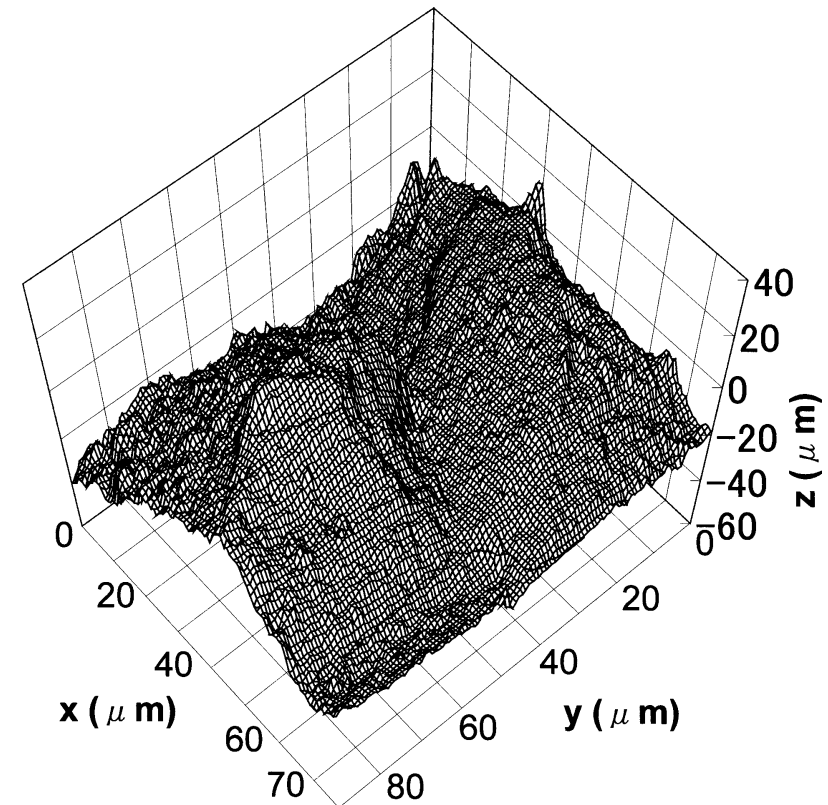

Fig. 5. Bird's eye-view of the three-dimensional stage I fatigue fracture surface in a $\mathrm{Cu}-\mathrm{Be}$ alloy.

shows the bird's-eye view of the same fracture surface. ${ }^{14)}$ Fine geometrical features of the fatigue fracture surface were reproduced in the three-dimensional image recon- 

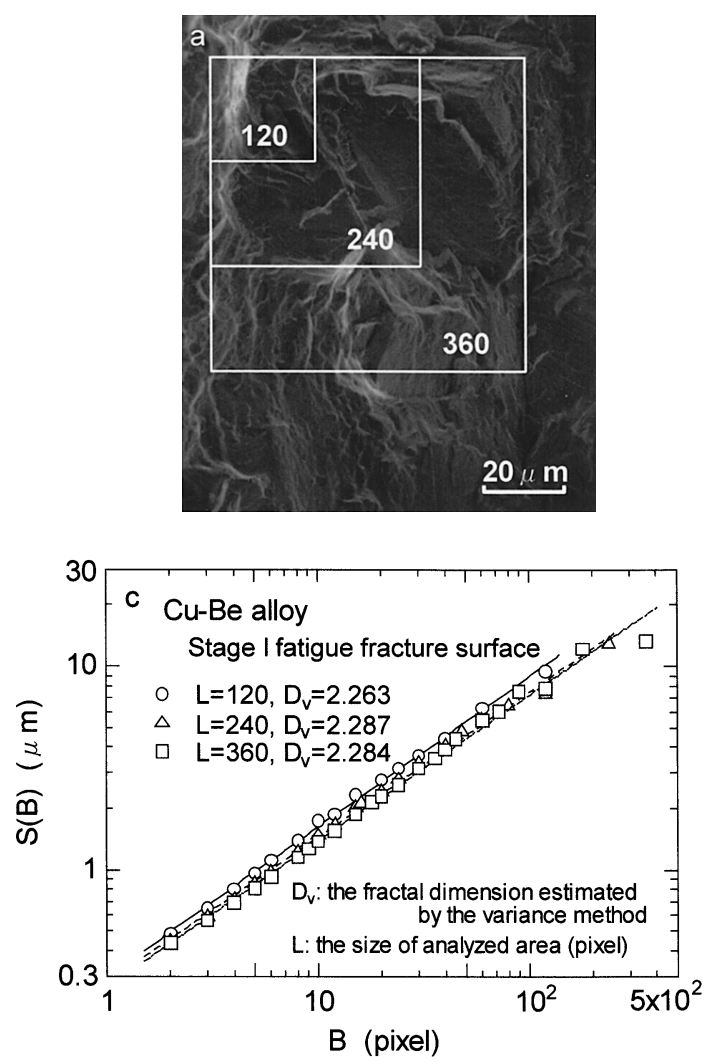
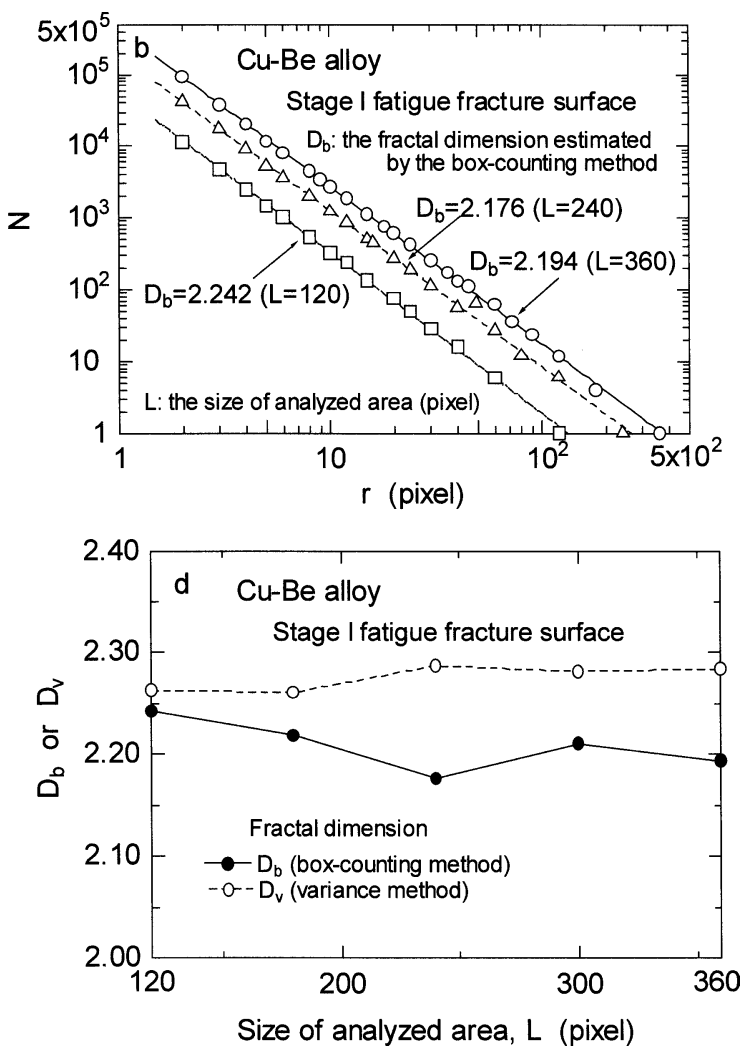

Fig. 6. Relationship between the size of the analyzed area $(L)$ and the fractal dimension of the stage I fatigue fracture surface in a $\mathrm{Cu}-\mathrm{Be}$ alloy. (a) is the original image and some regions for the fractal analysis; (b) is the fractal dimension estimated by the box-counting method $\left(D_{\mathrm{b}}\right) ;(\mathrm{c})$ is the fractal dimension estimated by the variance method $\left(D_{\mathrm{v}}\right)$; (d) is the relationship between the values of $D_{\mathrm{b}}$ or $D_{\mathrm{v}}$ and the size of the analyzed area ( $L$ in pixel).

struction. The crack growth direction is approximately from lower right to upper left in this figure. Figure 6 shows the relationship between the size of the analyzed area $(L)$ and the fractal dimension of the stage I fatigue fracture surface in a $\mathrm{Cu}-\mathrm{Be}$ alloy. Some regions for the fractal analysis are also shown in Fig. 6(a) (numerals are the analyzed areas in pixel). One pixel corresponds to about $1.81 \times 10^{-7} \mathrm{~m}$ in the figure. Figure 6(b) shows examples of the fractal dimension estimated by the box-counting method ( $N$ is the number of boxes covering the fracture surface and $r$ is the box size). In the variance method proposed by Almqvist, ${ }^{7)}$ a squared value of the average variance, $\{S(B)\}^{2}$, is expressed as:

$$
\{S(B)\}^{2}=\left\langle\frac{1}{B^{2}-1} \sum_{i=1}^{B^{2}}\left(Z_{i}-\bar{Z}\right)^{2}\right\rangle
$$

where $B$ is the size of the measurement boxes (pixel), $Z_{i}$ is the height in each point, $\bar{Z}$ is the average height in the box and \langle\rangle denotes averaging over all non-overlapping boxes covering the whole analyzed area. When the distance between datum points is the same, there is a relationship between the average variance, $\{S(B)\}$, and the size of the measurement boxes, $B$, to be expressed with the fractal dimension, $D_{\mathrm{v}}$, as ${ }^{7}$ :

$$
\{S(B)\} \propto B^{2\left(3-D_{v}\right)}
$$

As shown in Fig. 6(c), the fractal dimension, $D_{v}$, can be calculated from the least square regression line fit to the datum set of $\{S(B)\}$ and $B$ in a $\log -\log$ plot. Figure 6(d) shows that both fractal dimensions estimated by the box-counting

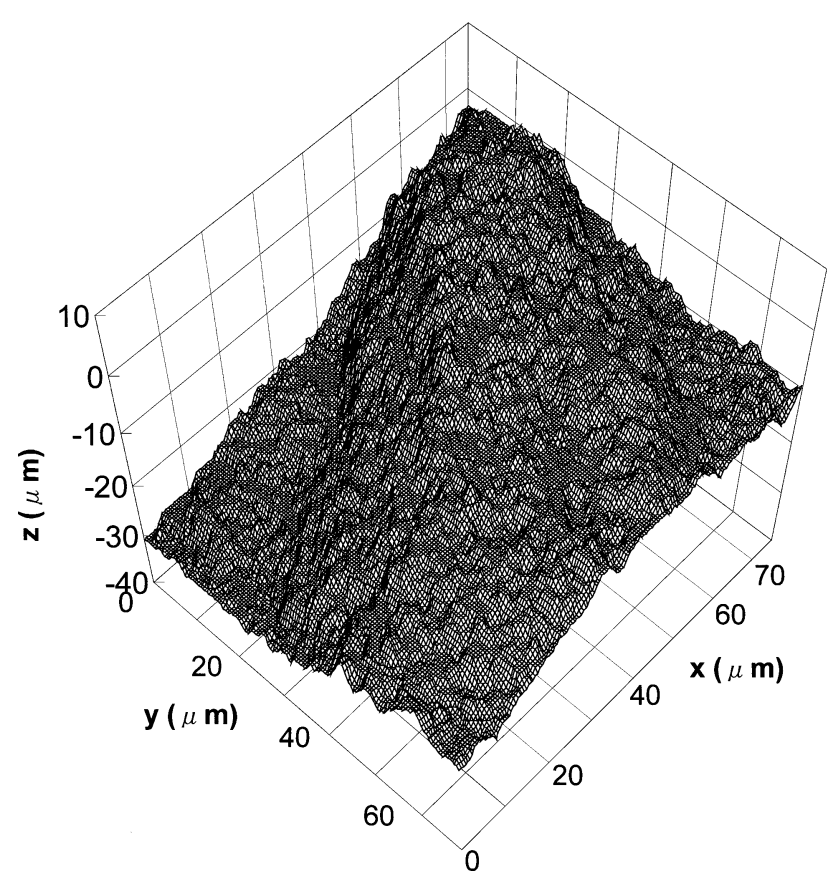

Fig. 7. Bird's eye-view of the three-dimensional impact fracture surface in a silicon carbide (Norton NC-430).

method, $D_{\mathrm{b}}$, and by the variance method, $D_{\mathrm{v}}$, do not largely change with the size of the analyzed area ( $L$ in pixel) in this case. The value of $D_{\mathrm{v}}$ is close to 2.30 and is a little larger than that of $D_{\mathrm{b}}$ (about 2.20).

Figure 7 shows the bird's-eye view of the three-dimensional impact fracture surface in a silicon carbide (Norton 

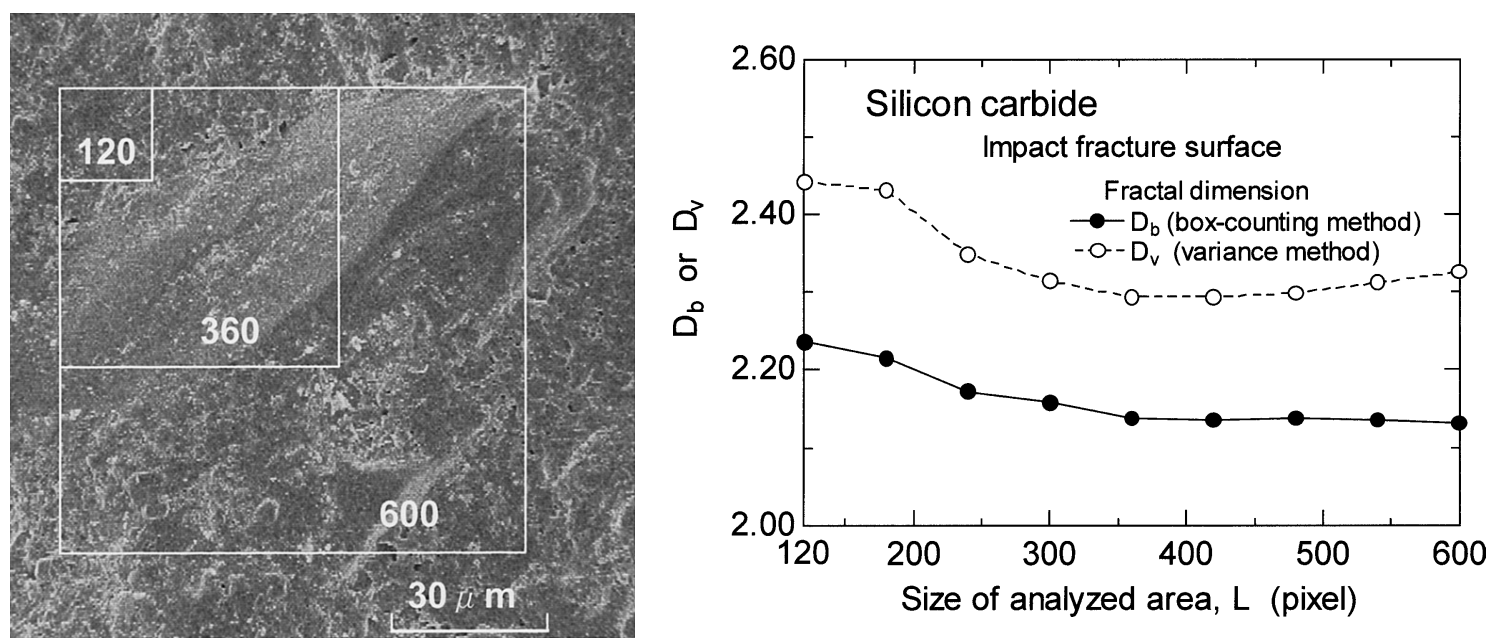

Fig. 8. Relationship between the size of the analyzed area ( $L$ in pixel) and the fractal dimension of the impact fracture surface in a silicon carbide (Norton NC-430).

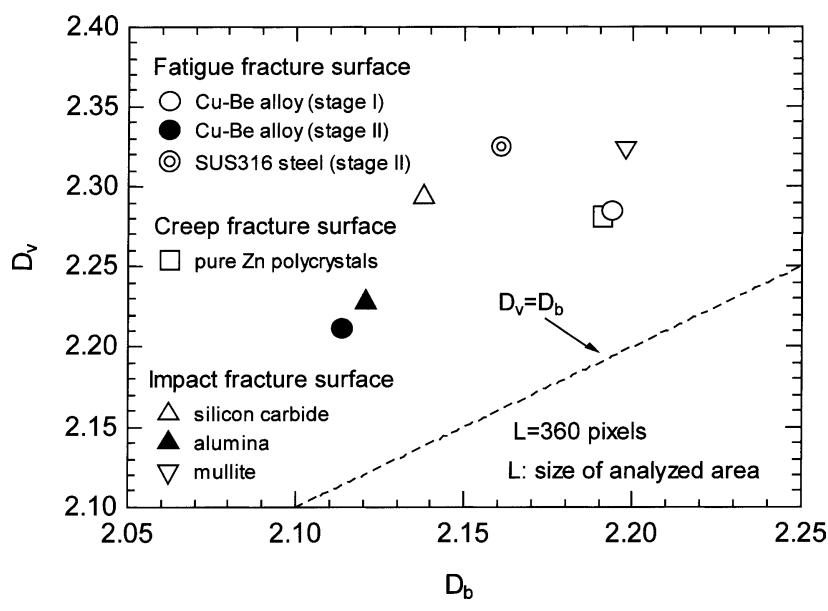

Fig. 9. Relationship between the fractal dimension estimated by the box-counting method, $D_{\mathrm{b}}$, and that estimated by the variance method, $D_{v}$, in metals and ceramics.

NC-430). Even very fine fracture patterns seem to be reconstructed in this image, whereas the fracture surface of the silicon carbide is somewhat simpler than that of a $\mathrm{Cu}-\mathrm{Be}$ alloy. Figure 8 shows the result of the fractal analysis on the impact fracture surface of a silicon carbide (Norton NC430). One pixel corresponds to about $1.13 \times 10^{-7} \mathrm{~m}$ in the photograph (numerals are the analyzed areas in pixel). When the size of the analyzed area is smallest ( $L=120$ pixels), the analyzed area involves only the part of complex geometry (the part of ductile fracture) and shows the highest value of the fractal dimension (both $D_{\mathrm{b}}$ and $D_{\mathrm{v}}$ in Fig. 8 ). Both values of $D_{\mathrm{b}}$ and $D_{\mathrm{v}}$ decrease with increasing size of the analyzed area $(L)$ because of the increased proportion of the flat part (the part of brittle-type fracture) in the analyzed area, but the values level off above $L=300$ pixels. The value of $D_{\mathrm{v}}$ is larger than that of $D_{\mathrm{b}}$ irrespective to the size of the analyzed area. The dependence of the fractal dimension on the size of the analyzed area can be correlated with microstructures on the fracture surface. Therefore, it is important for the fractal analysis to use an image large enough to involve principal microstructures on the fracture surface.

Figure 9 shows the relationship between the value of $D_{\mathrm{b}}$ and that of $D_{\mathrm{v}}$ on various fracture surfaces of materials estimated at the same analyzed area of $L=360$ pixels. The actual size of the analyzed area is equal to or larger than about $4.1 \times 10^{-5} \mathrm{~m}$ in this case. The length scale of the fractal analysis is in the range from two pixels to the analyzed area. The stage I fatigue fracture surface has the larger fractal dimension compared with the stage II fatigue fracture surface in a $\mathrm{Cu}-\mathrm{Be}$ alloy. As described in the Sec. 3.1, the stage I fatigue fracture surface is formed for the most part in a ductile manner with slip steps and dimples in a $\mathrm{Cu}-\mathrm{Be}$ alloy, while the stage II fatigue fracture surface is brittletype with grain-boundary facets and fine dimples. This suggests that ductile fracture surfaces have the larger fractal dimensions compared with brittle-type fracture surfaces in the same material. However, it is difficult to classify the type of fracture, namely, ductile fracture or brittle-type fracture, in different materials only by the fractal dimension of the fracture surface, since even fractal dimensions of brittle-type fracture surfaces exhibit different values with different materials, depending on the fracture mechanisms. There is a positive correlation between the values of $D_{\mathrm{b}}$ and those of $D_{\mathrm{v}}$, whereas the values of $D_{\mathrm{v}}$ are always larger than those of $D_{\mathrm{b}}$, irrespective of fracture mechanisms or fracture patterns. Thus, the value of the fractal dimension depends on the algorithms for the fractal analysis.

\subsection{Three-dimensional and Two-dimensional Fractal Analyses}

The fractal dimension of the fracture surface profiles or the indentation crack profiles, $D_{\mathrm{p}}\left(1<D_{\mathrm{p}}<2\right)$, was also estimated by the box-counting method. ${ }^{1,5)}$ Figure 10 shows examples of the fracture surface profiles and the indentation crack profiles and a schematic illustration of the two-dimensional box-counting method applied to the estimation of the fractal dimension, $D_{\mathrm{p}}$. Analyzed images are an optical micrograph of the stage I fatigue fracture surface profile (in the plane in parallel with the crack growth direction) in the $\mathrm{Cu}-\mathrm{Be}$ alloy (Fig. 10(a)) ${ }^{14)}$ and an indentation crack profile in a commercial alumina (SSA-999W) (Fig. $10(\mathrm{~b}))^{26)}$ Figure $10(\mathrm{c})$ shows the number of boxes, $N^{\prime}$, involving a fracture surface profile or an indentation crack profile, and the size of boxes, $r^{\prime}$ in the two-dimensional box-counting method. There is a relationship similar to Eq. 

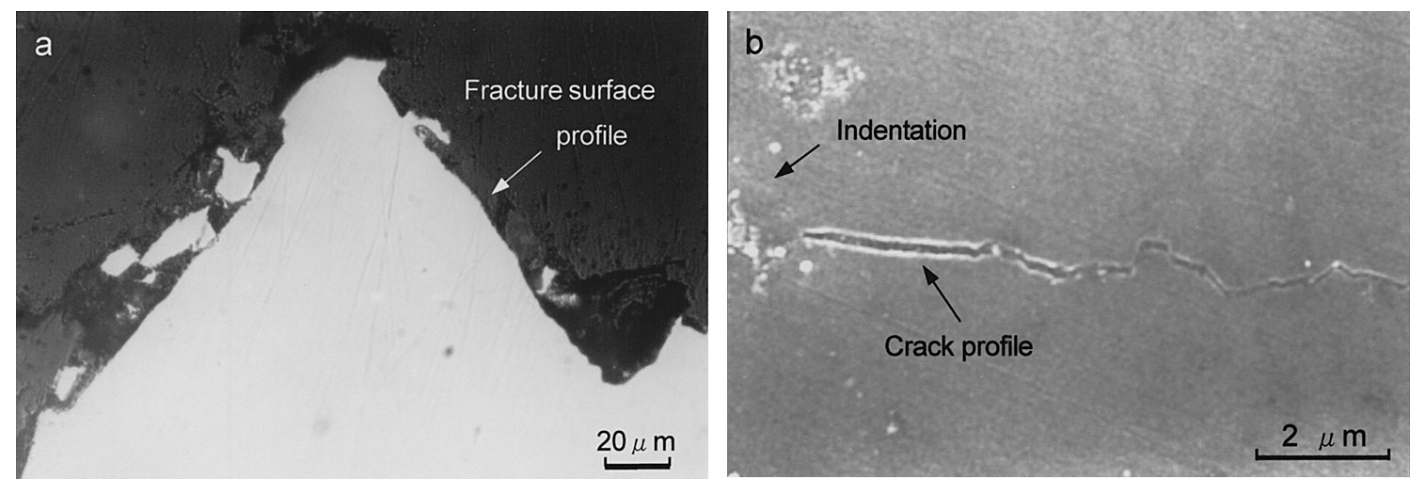

C

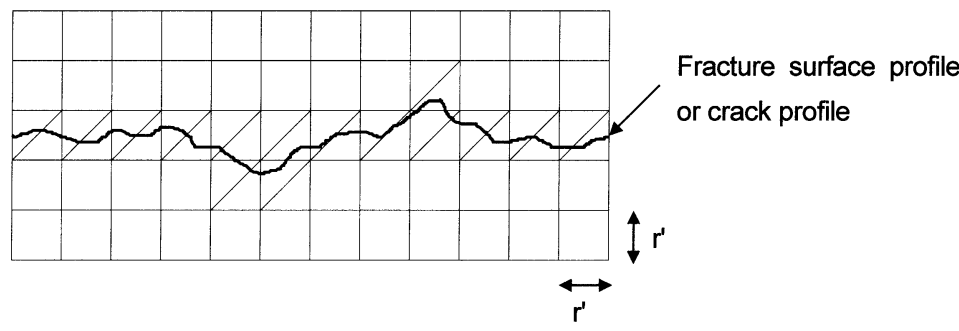

Fig. 10. Examples of the fracture surface profiles and the indentation crack profiles and a schematic illustration of the two-dimensional box-counting method applied to the estimation of the fractal dimension, $D_{\mathrm{p}}$. (a) is the stage I fatigue fracture surface profile in the $\mathrm{Cu}-\mathrm{Be}$ alloy ${ }^{14)}$; (b) is the indentation crack profile in a commercial alumina $(\mathrm{SSA}-999 \mathrm{~W})^{26)}$; (c) is the two-dimensional box-counting method $\left(N^{\prime}\right.$ is the number of boxes involving a fracture surface profile or an indentation crack profile, $r^{\prime}$ is the size of boxes and $N^{\prime}=15$ in this case).

(1) between the values of $N^{\prime}$ and those of $r^{\prime}$ with the fractal dimension, $D_{\mathrm{p}}$, such that $N^{\prime} \propto r^{\left.\prime-D_{\mathrm{p}} .{ }^{1.5}\right)}$ Therefore, the length of the profile, $L$, is given by the product of $N^{\prime}$ and $r^{\prime 27}$ :

$$
L=N^{\prime} r^{\prime}=L_{0} r^{\prime 1-D_{\mathrm{p}}}
$$

where $L_{0}$ is a constant. The values of $L$ and $r^{\prime}$ were fitted to Eq. (4) to obtain the value of $D_{\mathrm{p}}$ by the regression analysis. Figure 11 shows the results of the two-dimensional fractal analysis on the fracture surface profiles and the indentation crack profiles of Fig. 10. The slope of the linear relationship between $L$ and $r^{\prime}$ gives the fractal dimension of the fracture surface profiles or the indentation crack profiles, $D_{\mathrm{p}}$. The value of $D_{\mathrm{p}}$ was estimated in the length scale range of the fractal analysis smaller than about one grain-boundary length (about $1.4 \times 10^{-5} \mathrm{~m}$ ) for the stage I fatigue fracture surface profile in the $\mathrm{Cu}-\mathrm{Be}$ alloy. ${ }^{14,22)}$ The value of $D_{\mathrm{p}}$ was estimated in the length scale range from $2.7 \times 10^{-8} \mathrm{~m}$ to $8.2 \times 10^{-7} \mathrm{~m}$ for the indentation crack profile of SSA-999W alumina, which was associated with the grain size range $\left(9.9 \times 10^{-8} \mathrm{~m}\right.$ to $\left.7.5 \times 10^{-7} \mathrm{~m}\right)$.

Table 1 lists the fractal dimension of the three-dimensional fracture surface, $D_{\mathrm{b}}$, and that of the fracture surface profile or the indentation crack profile, $D_{\mathrm{p}}$, in metals and ceramics. The size of the analyzed area in the three-dimensional fractal analysis is equal to or larger than about $6.5 \times 10^{-5} \mathrm{~m}$. Both fractal dimensions were estimated in the length scale range smaller than the grain size or smaller than about one grain-boundary length, since the sizes of microstructures such as slip steps, dimples and grainboundary steps on the fracture surfaces are smaller than the grain size or one grain-boundary length. About 8 grains were involved in the analyzed area $(360 \times 360$ in pixel) of the stage I fatigue fracture surface in the $\mathrm{Cu}-\mathrm{Be}$ alloy, while about 10 grains were included in the analyzed area

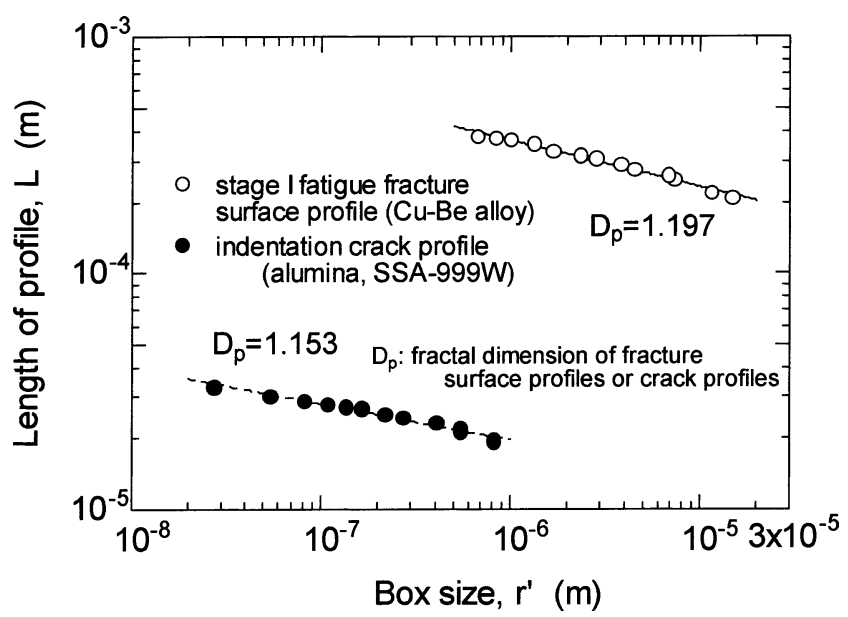

Fig. 11. The results of the two-dimensional fractal analysis on the stage I fatigue fracture surface profile in a $\mathrm{Cu}-\mathrm{Be}$ alloy and of the indentation crack profile in an alumina (SSA-999W) of Fig. 10

$(600 \times 600$ in pixel) of the stage II fatigue fracture surface. The analyzed area of the stage II fatigue fracture surface $(360 \times 360$ in pixel) involved about 25 grains in the SUS316 steel. Much larger number of grains seemed to be involved in the fracture surfaces of the ceramics. Thus, the three-dimensional fractal analysis was carried out in relatively wide areas of fracture surfaces in this study. In a $\mathrm{Cu}-\mathrm{Be}$ alloy, the length scale range of the fractal analysis is associated with the size range of slip steps in the stage I fatigue fracture surface (about $6 \times 10^{-7} \mathrm{~m}$ to about $5 \times 10^{-6} \mathrm{~m}$ ), and is also related to the size range of dimples (about $3.5 \times 10^{-7} \mathrm{~m}$ to about $9.0 \times 10^{-6} \mathrm{~m}$ ) or that of grain-boundary steps (about $4 \times 10^{-6} \mathrm{~m}$ to about $3 \times 10^{-5} \mathrm{~m}$ ) in both the stage I and stage II fatigue fracture surfaces. ${ }^{22)}$ The length scale range of the 
Table 1. The fractal dimension of the three-dimensional fracture surface, $D_{\mathrm{b}}$, and that of the fracture surface profile or the indentation crack profile, $D_{\mathrm{p}}$, in metals and ceramics.

\begin{tabular}{|c|c|c|c|c|c|}
\hline Materials & $\begin{array}{l}\text { Conditions of } \\
\text { fracture surface }\end{array}$ & $\begin{array}{c}\text { Average grain size (GS) } \\
\text { or grain-boundary } \\
\text { length }(\mathrm{GBL}), \mathrm{m} \\
\text { (grain size range, m) }\end{array}$ & $\begin{array}{l}\mathrm{D}_{\mathrm{b}} \\
\text { (length scale range for } \\
\text { fractal analysis, m) }\end{array}$ & \multicolumn{2}{|c|}{$\begin{array}{l}\mathrm{D}_{\mathrm{p}} \\
\text { (length scale range for } \\
\text { fractal analysis, m) }\end{array}$} \\
\hline \multirow{2}{*}{$\mathrm{Cu}-\mathrm{Be}$ alloy } & \multirow{2}{*}{$\begin{array}{l}\text { Stage I fatigue } \\
\text { fracture surface }\end{array}$} & \multirow{3}{*}{$\begin{array}{c}\mathrm{GS}=2.4 \times 10^{-5} \\
\mathrm{GBL}=1.4 \times 10^{-5}\end{array}$} & \multirow{2}{*}{$\begin{array}{c}2.164 \\
\left(3.6 \times 10^{-7} \text { to } 1.3 \times 10^{-5}\right)\end{array}$} & $\mathrm{P}$ & $\begin{array}{c}1.210 \\
\left(6.7 \times 10^{-7} \text { to } 1.7 \times 10^{-5}\right)\end{array}$ \\
\hline & & & & $\mathrm{T}$ & $\begin{array}{c}1.190 \\
\left(6.7 \times 10^{-7} \text { to } 1.7 \times 10^{-5}\right)\end{array}$ \\
\hline $\mathrm{Cu}-\mathrm{Be}$ alloy & $\begin{array}{l}\text { Stage II fatigue } \\
\text { fracture surface }\end{array}$ & & $\begin{array}{c}2.116 \\
\left(2.4 \times 10^{-7} \text { to } 1.4 \times 10^{-5}\right) \\
\end{array}$ & \multicolumn{2}{|c|}{$\begin{array}{c}1.168 \\
\left(6.7 \times 10^{-7} \text { to } 1.7 \times 10^{-5}\right) \\
\end{array}$} \\
\hline SUS316 steel & $\begin{array}{l}\text { Stage II fatigue } \\
\text { fracture surface }\end{array}$ & $\begin{array}{l}\mathrm{GS}=1.3 \times 10^{-5} \\
\mathrm{GBL}=8 \times 10^{-6}\end{array}$ & $\begin{array}{c}2.198 \\
\left(3.6 \times 10^{-7} \text { to } 8.1 \times 10^{-6}\right)\end{array}$ & \multicolumn{2}{|c|}{$\begin{array}{c}1.221 \\
\left(6.7 \times 10^{-7} \text { to } 8.3 \times 10^{-6}\right) \\
\end{array}$} \\
\hline $\begin{array}{c}\text { Silicon carbide } \\
\text { (Norton NC-430) }\end{array}$ & $\begin{array}{c}\text { Impact fracture } \\
\text { surface }\end{array}$ & $\begin{array}{c}\mathrm{GS}=1.3 \times 10^{-5} \\
\left(3.7 \times 10^{-7} \text { to } 8.6 \times 10^{-5}\right)\end{array}$ & $\begin{array}{c}2.189 \\
\left(2.3 \times 10^{-7} \text { to } 5.7 \times 10^{-6}\right) \\
\end{array}$ & \multicolumn{2}{|c|}{$\begin{array}{c}1.16^{*} \\
\left(2.7 \times 10^{-7} \text { to } 5.5 \times 10^{-6}\right)\end{array}$} \\
\hline $\begin{array}{c}\text { Alumina } \\
(\mathrm{SSA}-\mathrm{H}) \\
\end{array}$ & $\begin{array}{c}\text { Impact fracture } \\
\text { surface }\end{array}$ & $\begin{array}{c}\mathrm{GS}=3.0 \times 10^{-6} \\
\left(6.4 \times 10^{-7} \text { to } 9.2 \times 10^{-6}\right)\end{array}$ & $\begin{array}{c}2.134 \\
\left(3.0 \times 10^{-7} \text { to } 8.9 \times 10^{-6}\right) \\
\end{array}$ & \multicolumn{2}{|r|}{$1.15^{* *}$ to $1.19^{* *}$} \\
\hline
\end{tabular}

$\mathrm{P}$ : in the plane in parallel with the crack growth direction ${ }^{22)}$; $\mathrm{T}$ in the plane transverse to the crack growth direction, *: the value for indentation crack ${ }^{26)}, * *$ : the values for indentation cracks in similar alumina ${ }^{26)}$.

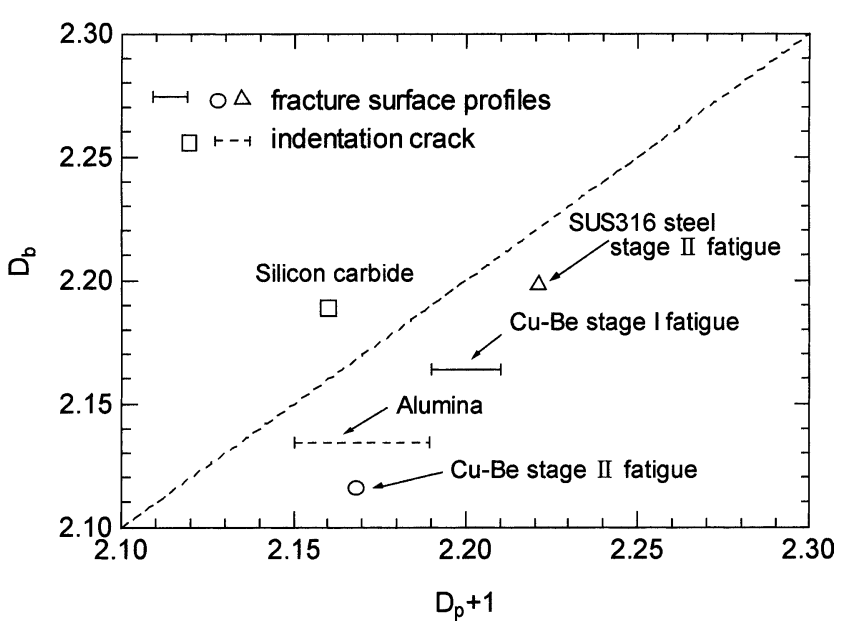

Fig. 12. Relationship between the fractal dimension of the threedimensional fracture surface, $D_{\mathrm{b}}$, and the fractal dimension, $D_{\mathrm{p}}+1$, predicted by the two-dimensional fractal analysis in metals and ceramics.

fractal analysis is associated with the striation spacing (about $5 \times 10^{-7} \mathrm{~m}$ to about $6 \times 10^{-6} \mathrm{~m}$ ) in the stage II fatigue fracture surface of the SUS316 steel. ${ }^{22}$ ) Therefore, the fractal dimension can be correlated with specific microstructures in materials.

The fractal dimension of a surface can be predicted by adding unity to the fractal dimension of its cross-section from general properties of fractal sets. ${ }^{28)}$ Figure 12 shows the relationship between the fractal dimension of the threedimensional fracture surface, $D_{\mathrm{b}}$, and the fractal dimension, $D_{\mathrm{p}}+1$, predicted by the two-dimensional fractal analysis in metals and ceramics. The length scale range of the fractal analysis is shown in Table 1. As described in Sec. 3.1, the fracture mechanisms and fracture patterns are quite different in metals and ceramics. However, the stage I (ductile) fatigue fracture surface has the larger value of the fractal dimension compared with the stage II (brittle-type) fatigue fracture surface in a $\mathrm{Cu}-\mathrm{Be}$ alloy. The value of $D_{\mathrm{b}}$ is close to that of $D_{\mathrm{p}}+1$ in materials examined in this study, although the former value is slightly smaller than the latter value in most cases. This may indicate that principal fracture surface patterns like slip steps, dimples or micropores can be reproduced by the stereo matching method. However, there seems to be other microstructural features like overhang and debris generated by crack overlapping and microcracks linked to the fracture surfaces, ${ }^{29)}$ which are only partly reproducible by the stereo matching method and may not fully be detected by scanning probe microscopes. This may be why the value of $D_{\mathrm{b}}$ is slightly smaller than that of $D_{\mathrm{p}}+1$ in these materials.

\section{Conclusions}

Three-dimensional fracture surfaces of metals and ceramics produced by different mechanisms were reconstructed by the computer-aided stereo matching method. The fractal dimension of the three-dimensional fracture surface were estimated by the box-counting method using the height data generated by the stereo matching method. The ductile fracture surface (stage I fatigue) had the larger fractal dimension compared with the brittle-type fracture surface (stage II fatigue) in a $\mathrm{Cu}-\mathrm{Be}$ alloy. However, it was difficult to classify the type of fracture, namely, ductile fracture or brittle-type fracture, in different materials only by the fractal dimension of the fracture surface, since even fractal dimensions of brittle-type fracture surfaces exhibited different values with different materials, depending on the fracture mechanisms of materials. There was a good correlation between the results of the three-dimensional fractal analysis and those of the two-dimensional fractal analysis on the fracture surfaces of materials. The value of the fractal dimension of the three-dimensional fracture surface depends not only on the size of the analyzed area but also on the algorithms of the fractal analysis. The fractal dimension estimated by the variance method was larger than that evaluated by the box-counting method, irrespective of fracture mechanisms of materials. The fractal dimension estimated in a given length scale range can be correlated with specific microstructures in materials. The three-dimensional fractal analysis by the box-counting method is essentially applica- 
ble to any surfaces, if the information in the height direction is obtained.

\section{Acknowledgements}

The authors thank The Iron and Steel Institute of Japan (Tekkou-Kenkyu-Josei) for financial support.

\section{REFERENCES}

1) B. B. Mandelbrot: The Fractal Geometry of Nature, translated by H. Hironaka, Nikkei Science, Tokyo, (1985), 108.

2) B. B. Mandelbrot, D. E. Passoja and A. J. Paullay: Nature, 308 (1984), 721.

3) P. Streitenberger and D. Forster: Phys. Status Solidi, B171 (1992), 21

4) M. Takahashi and H. Hasegawa: Fractals, 8 (2000), 189

5) H. Takayasu: Fractals in the Physical Sciences, Manchester University Press, Manchester and New York, (1990), 6.

6) V. Y. Milman, N. A. Stelmashenko and R. Blumenfeld: Prog. Mater. Sci., 38 (1994), 425.

7) N. Almqvist: Surf. Sci., 355 (1996), 221

8) U. Wendt, K. Stiebe-Lange and M. Smid: J. Microsc., 207 (2002), 169.

9) K. Komai and J. Kikuchi: J. Soc. Mater. Sci. Jpn., 34 (1985), 648.

10) T. Kobayashi and D. A. Shockey: Metall. Trans., 18A (1987), 1941.

11) J. Stampfl, S. Scherer, M. Berchthaler, M. Gruber and O. Kolednik: Int. J. Fract., 78 (1996), 35.

12) J. Stampfl and O. Kolednik: Int. J. Fract., 101 (2000), 321.
13) Y. Kimura and M. Tanaka: Proc. 4th Int. Conf. on Materials for Resources, Vol. 2, The Society of Materials Engineering for Resources of Japan, Akita, (2001), 249.

14) M. Tanaka, Y. Kimura, L. Chouanine, J. Taguchi and R. Kato: ISIJ Int., 43 (2003), 1453.

15) M. Tanaka, Y. Kimura, R. Kato and J. Taguchi: J. Mater. Sci. Lett., 22 (2003), 1279

16) R. H. Dauskardt, F. Haubensak and R. O. Ritchie: Acta Metall, 38 (1990), 142

17) M. Tanaka and H. Iizuka: Z. Metallkd., 82 (1991), 442.

18) M. Tanaka: J. Mater. Sci., 27 (1992), 4717.

19) M. Tanaka: Z. Metallkd., 84 (1993), 697.

20) M. Tanaka: J. Mater. Sci., 28 (1993), 5753.

21) T. Ikeshoji and T. Shioya: Fractals, 7 (1999), 159.

22) M. Tanaka, A. Kayama and R. Kato: J. Mater. Sci. Lett., 18 (1999), 107.

23) M. Tanaka, R. Kato and A. Kayama: J. Mater. Sci., 37 (2002), 3945.

24) M. Tanaka, A. Kayama, Y. Sato and Y. Ito: J. Mater. Sci. Lett., 17 (1998), 1715

25) M. Tanaka: J. Mater. Sci., 31 (1996), 749

26) M. Tanaka: J. Soc. Mater. Sci. Jpn., 47 (1998), 169.

27) B. B. Mandelbrot: The Fractal Geometry of Nature, translated by $\mathrm{H}$. Hironaka, Nikkei Science, Tokyo, (1985), 25.

28) H. Takayasu: Fractals in the Physical Sciences, Manchester University Press, Manchester and New York, (1990), 20.

29) D. Hull: Fractography, Cambridge University Press, Cambridge, (1999), 118. 